\title{
CUIDADO EM GRUPOS DE IDOSOS PARA O CONVÍVIO COM O RISCO DE CONTÁGIO POR CORONAVÍRUS
}

\author{
Angela Maria Alvarez' \\ ORCID: 0000-0002-2622-3494
}

Maristela Assumpção Azevedo"

ORCID: 0000-0003-1104-5135

Adriana Remião Luzardo"'I ORCID: 0000-0002-9240-0065

Carla Argentaiv

ORCID: 0000-0002-9729-410X

Josiane S. Steil ${ }^{\mathbf{V}}$

ORCID: 0000-0002-8952-2360

Juliana Martins Ferreira'

ORCID: 0000-0001-6326-4917

'Universidade Federal de Santa Catarina. Florianópolis, Santa Catarina, Brasil.

"Centro Universitário Estácio. São José, Santa Catarina, Brasil.

'"Universidade Federal da Fronteira Sul. Chapecó, Santa Catarina, Brasil.

IV Universidade do Estado de Santa Catarina. Florianópolis, Santa Catarina, Brasil.

VInstituto Federal de Santa Catarina. Joinville. Santa Catarina, Brasil.

Autor Correspondente: Ângela Maria Alvarez angela.alvarez@ufsc.br

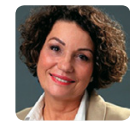

Como citar:

Alvarez AM, Azevedo MA, Luzardo AR, Argenta C, Steil JS, Ferreira JM. Cuidado de Enfermagem em Grupos de Idosos com Risco de Contágio por Coronavírus. In: Santana RF (Org.). Enfermagem gerontológica no cuidado do idoso em tempos da COVID 19. Brasilia, DF: Editora ABen;

2021. 171 p. (Serie Enfermagem e Pandemias, 5). https://doi.org/10.51234/aben.21.e05 c05

\section{INTRODUÇÃO}

Diante do acometimento das pessoas idosas como principal grupo de risco para uma nova doença, a SARS-CoV-2 (Severe Acute Respiratory Syndrome Coronavirus 2), exige uma atuação do enfermeiro a partir de uma perspectiva humanística. Na qual seu olhar se debruce sobre o isolamento social da pessoa idosa, que neste momento confronta-se com o risco da contaminação pela COVID 19 (Corona Virus Disease) e a possibilidade de adoecer.

Entre os idosos, o risco de contrair a doença é significativo e aumenta com a idade, estimando-se que a mortalidade aumente linearmente: 3,6\% na faixa etária entre $60-69 ; 8 \%$ entre $70-79$ anos e $14,8 \%$ entre 80 e mais de idade, mormente quando associada às comorbidades comuns nesse grupo. Soma-se a isso a necessidade de serem cuidadas e atendidas por outras pessoas e pelas relações familiares, aumentando o risco de transmitir a doença ${ }^{(1-2)}$.

A realidade de uma doença com alto potencial de transmissibilidade impôs restrições à movimentação das pessoas idosas, que se recolheram, diminuindo significativamente suas atividades extradomiciliares, em detrimento da interação social, principalmente daqueles pertencentes ao grupo e idosos independentes e mais ativos.

Em nossa sociedade, os idosos buscam estar integrados com atividades de convivência na comunidade, sendo convidados a participarem de grupos de educação em saúde nas Unidades Básicas de Saúde, entre outros projetos comunitários. A ideia de trabalhar com grupos já é antiga, e a enfermagem trabalha com grupos variados, que a enfermeira tem à disposição para ação multiprofissional e interdisciplinar, assumindo liderança nas unidades de saúde e realizando educação em serviço, educação em saúde e organizando grupos.

Ao cuidar em grupo, a enfermeira atua sob uma perspectiva humanística que lhe permite, numa posição de horizontalidade, aproximar-se da realidade das pessoas e da coletividade ${ }^{(3)}$. 
Ao propiciar momentos de solidariedade, cooperação, superação e estímulo à pessoa idosa, o cuidado em grupo promove informação e inserção social na perspectiva da promoção da saúde. O cuidado socioeducativo em grupo é um espaço de educação em saúde, tanto por suas características educativa como participativa ${ }^{(4)}$.

No entanto, a experiência da pandemia neste início de século surpreendeu o mundo todo e modificou nossa forma de viver o dia a dia trazendo novos desafios aos cuidados de enfermagem a grupos de idosos. Neste momento, vemo-nos diante da necessidade de rever nossa prática de trabalho com grupos de idosos para a promoção de um viver saudável.

Os profissionais vêm preparando-se para atender essa nova demanda da população idosa, mas é imprescindível o envolvimento das pessoas para que possam enfrentar o risco e se prevenir contra a doença, por meio do estímulo ao autocuidado e de informações e orientações adequadas.

Assim, o presente estudo teve como objetivo: refletir acerca do cuidado de enfermagem e propor estratégias para o convívio com o risco do contágio por coronavírus em atividades de grupo.

\section{MÉTODO}

Estudo teórico, desenvolvido com aporte da literatura nacional e internacional sobre o tema proposto. Com base no material selecionado, foi realizada reflexão teórico-prática com a finalidade de propor estratégias de enfrentamento da pandemia por meio dos encontros de grupos de idosos na comunidade.

\section{Os Grupos de Idosos}

Em várias de suas diretrizes, o Sistema Único de Saúde (SUS) traz políticas públicas relacionadas à população idosa ${ }^{(5)}$. A Política Nacional de Atenção Básica ${ }^{(6-7)}$ preconiza ações terapêuticas em grupos na Atenção Primária à Saúde (APS) de acordo com as necessidades dos idosos identificadas pelos profissionais que realizam planos e projetos para atuarem com os idosos como oficina: esportivas, terapêuticas, criativas, culturais, suporte social, entre outras ${ }^{(5-8)}$. O cuidado em grupo reúne as pessoas em torno de uma atividade em comum. É um espaço para troca de experiências em que cada um pode expor suas potencialidades e trabalhar suas vulnerabilidades, elevando sua autoestima. Além disso, propicia a ampliação do vínculo entre a equipe e a pessoa idosa, num espaço de educação em saúde como fonte de conhecimento e troca de informações.

Os Grupos de Educação em saúde promovem atividades que fazem parte do cotidiano dos profissionais na APS: os idosos estão incluídos em grupos que tratam de doenças crônicas, como diabetes e hipertensão, e que geralmente são chamados de grupos de idosos, embora não tratem do envelhecimento, mas de doenças crônicas ${ }^{(5)}$.

Os grupos de educação em saúde com idosos trazem muitos benefícios ao favorecer o compartilhamento de informações e experiências entre todos os membros, empoderando os sujeitos por meio da relação dialógica com os profissionais. Num contexto de pandemia, os encontros dos grupos e celebrações desses contatos se modificam, por exigência dos cuidados necessários para evitar disseminação do vírus pela aglomeração de pessoas.

Os grupos de convivência têm por finalidade oferecer ao idoso a garantia de conviver $\mathrm{cm}$ oportunidades de ações estratégicas para: enfrentar circunstâncias adversas; promover a formação de vínculos e a construção ou a recuperação de projetos pessoais e sociais; proporcionar a permanência do idoso na sociedade por meio de atividades voltadas para esse público e incentivar a inclusão social ${ }^{(9-10)}$.

\section{Autocuidado como Fundamento Teórico para o Cuidado em Grupo na Prevenção da COVID-19}

A enfermeira Dorothea Orem desenvolveu a teoria geral de enfermagem também conhecida como a teoria de enfermagem do déficit de autocuidado, composta de três teorias inter-relacionadas: teoria do autocuidado, teoria do déficit de autocuidado e teoria dos sistemas de enfermagem. Considerando as demandas de cuidados em saúde de grupos de idosos, no presente estudo foi utilizada a teoria do autocuidado (11). 
O autocuidado é "uma ação deliberada para suprir ou garantir o fornecimento dos materiais necessários para continuar a vida, o crescimento e o desenvolvimento e a manutenção da integridade humana"(12). $\mathrm{O}$ enfermeiro deve atuar de modo complementar com as pessoas, famílias e comunidade no exercício do autocuidado. Deve reforçar a participação ativa das pessoas no seu autocuidado, como responsáveis pelas decisões relacionadas a sua situação de saúde. O enfermeiro deve ajudar o indivíduo a desenvolver e implementar essas ações de autocuidado de forma que a pessoa possa recuperar-se ou enfrentar as consequências do agravo em saúde ${ }^{(11)}$.

Premissa importante na teoria de Orem são as relações. Para ela, as pessoas envolvem-se em trocas e comunicações contínuas mútuas e com seu ambiente de forma a continuarem vivos. Grupo de pessoas com relacionamentos estruturados pode dividir tarefas e responsabilidades para prestar cuidados aos membros do grupo incapazes para o autocuidado ${ }^{(13)}$. Considerando o cenário de cuidado apresentado - grupos de idosos - é importante que o enfermeiro compreenda como o autocuidado pode promover a saúde dos idosos, de seus familiares e de profissionais participantes, compreendendo também o papel das relações no desenvolvimento do autocuidado.

As estratégias de cuidado com idosos em atividade de grupo exigem informação adequada e estímulo ao autocuidado. No entanto, desenvolver novos hábitos pode não ser tão fácil para pessoas idosas, cujo modo de vida e de enfrentar as situações novas já estão sedimentadas. Por isso, o olhar do enfermeiro deve sempre repousar nas capacidades e potencialidades dessas pessoas idosas, pois assim como chegaram à plenitude da velhice, elas também se constituíram com habilidades que lhes permitem aprender coisas novas, lidar com os preconceitos e lutar por independência e autonomia.

\section{RESULTADOS}

\section{Diagnósticos, Intervenções e Resultados Esperados para o Cuidado em Grupo na Prevenção dos Riscos de Contaminação}

Para desenvolver uma prática de enfermagem com pessoas idosas é fundamental que a enfermeira tenha em mente o raciocínio clínico, de maneira a identificar os déficits de autocuidado e ao mesmo tempo orientá-las sobre como devem agir para proteger-se. O Processo de Enfermagem orienta esse raciocínio e a tomada de decisão sobre o cuidado individual e coletivo, pois permite o olhar sobre a integralidade de cada membro do grupo.

Sendo assim, a enfermeira, que exerce função de liderança na maioria dos espaços, precisa sistematizar o cuidado aos idosos do grupo de risco para coronavírus, a fim de estabelecer estratégias para desenvolver comportamentos de autocuidado dos idosos e da equipe. Além de propiciar e favorecer que o espaço seja seguro e as atividades se desenvolvam em segurança. Para isso, aposta-se na predeterminação de diagnósticos, intervenções e resultados de enfermagem compatíveis com fatores de risco que são comuns a todos, intervenções abrangentes direcionadas ao indivíduo, família e comunidade e resultados capazes de realizar uma avaliação criteriosa acerca da prevenção da contaminação pelo SARS-CoV-2.

Pensando em auxiliar enfermeiros nesse contexto de prevenção, a Rede de Pesquisa em Processo de Enfermagem (RePPE) elaborou documento com um compilado de diagnósticos de enfermagem e suas ligações com base nos sistemas de linguagens padronizadas de Enfermagem. Para tanto, nos Quadros 1 e 2 mostram-se Diagnósticos, Intervenções e Resultados de Enfermagem que podem ser utilizados pelo enfermeiro na prática de cuidado aos idosos que participam de atividades grupais. Tais informações foram extraídas do documento construído pela RePEE e adaptado para as atividades grupais e suas especificidades. Nesse sentido, diagnósticos, resultados esperados e intervenções para prevenir a COVID-19 em atividades grupais são apresentados nos Quadros 1e 2: 
Quadro 1 - Diagnósticos, resultados e intervenções de enfermagem para prevenir a COVID-19 em atividades grupais (FOCO NO GRUPO E NA EQUIPE).

\begin{tabular}{|c|c|c|c|}
\hline $\begin{array}{l}\text { Diagnóstico de } \\
\text { Enfermagem }\end{array}$ & $\begin{array}{l}\text { Resultados de } \\
\text { Enfermagem (NOC) }\end{array}$ & $\begin{array}{l}\text { Intervenções de } \\
\text { Enfermagem (NIC) }\end{array}$ & Atividades/Prescrição de Enfermagem \\
\hline $\begin{array}{l}\text { [ ] Risco de } \\
\text { contaminação }\end{array}$ & $\begin{array}{l}\text { [ ] Resposta comunitária } \\
\text { a catástrofes } \\
\text { Escore: } \\
\text { [ ] levemente adequado } \\
\text { [ ] moderadamente } \\
\text { adequado } \\
\text { [ ] substancialmente } \\
\text { adequado } \\
\text { [ ] totalmente adequado } \\
\text { [ ] Controle de Riscos } \\
\text { comunitário: } \\
\text { Escore: } \\
\text { [ ] razoável } \\
\text { [ ] bom } \\
\text { [ ] muito bom } \\
\text { [ ] excelente } \\
\text { [ ] Enfrentamento } \\
\text { comunitário } \\
\text { Escore: } \\
\text { [ ] razoável } \\
\text { [ ] bom } \\
\text { [ ] muito bom } \\
\text { [ ] excelente } \\
\text { [ ] Controle de Riscos: } \\
\text { processo infecioso } \\
\text { Escore: } \\
\text { [ ] raramente } \\
\text { [ ] algumas vezes } \\
\text { [ ] frequentemente } \\
\text { [ ] consistentemente } \\
\text { demonstrado } \\
\text { [ ] Controle dos Sintomas } \\
\text { Escore: } \\
\text { [ ] raramente } \\
\text { [ ] algumas vezes } \\
\text { [ ] frequentemente } \\
\text { [ ] consistentemente } \\
\text { demonstrado }\end{array}$ & $\begin{array}{l}\text { [ ] Proteção contra } \\
\text { infecção } \\
\text { [ ] Identificação de } \\
\text { Risco } \\
\text { [ ] Controle de } \\
\text { Imunização/ } \\
\text { Vacinação } \\
\text { [ ] Ensino: Processo } \\
\text { de Doença } \\
\text { [ ] Controle de } \\
\text { Infecção } \\
\text { [ ] Supervisionar }\end{array}$ & $\begin{array}{l}\text { [ ] Orientar os participantes a não comparecerem ao } \\
\text { grupo em caso de sinais e sintomas gripais da pessoa ou } \\
\text { de membros familiares ou pessoas próximas. } \\
\text { [ ] Avaliar e registrar a rede de contatos do idoso e da } \\
\text { equipe com suspeitos da COVID-19. } \\
\text { [ ] Verificar e registrar a temperatura, oximetria e as } \\
\text { respostas do idoso sobre sinais e sintomas de Covid (dor } \\
\text { de garganta, cansaço, tosse, perda olfato ou paladar) na } \\
\text { chegada dos participantes. } \\
\text { [ ] Desenvolver/ Implementar protocolos de conduta } \\
\text { mediante identificação de casos suspeitos de idosos e } \\
\text { equipe.? } \\
\text { [ ] Manter isolamento de contato por gotículas } \\
\text { orientando e supervisionando o uso da máscara de } \\
\text { tecido, o distanciamento de } 1 \text { metro e meio de distância. } \\
\text { [ ] Implementar entre os membros do grupo formas de } \\
\text { cumprimento sem contato físico. Ex.: acenando com } \\
\text { as mãos, cumprimentar com cotovelo, com os pés, } \\
\text { curvando-se respeitosamente diante do amigo e outros. } \\
\text { [ ] Orientar e supervisionar a higiene das mãos e o uso } \\
\text { de álcool gel individual. Ex.: produzir e transmitir vídeos } \\
\text { ou desenvolver aulas práticas } \\
\text { [ ] Orientar idosos e membros das equipe sobre os sinais } \\
\text { e sintomas de infecção. } \\
\text { [ ] Avaliar hábitos de higiene pessoal do idoso e da } \\
\text { equipe por meio da observação constante durante as } \\
\text { atividades. } \\
\text { [ ] Investigar a falta de conhecimento dos idosos e da } \\
\text { equipe sobre as medidas de precaução de contato. } \\
\text { [ ] Orientar idosos e membros da equipe para o uso } \\
\text { adequado de EPI (Equipamento de proteção individual). } \\
\text { [ ] Orientar idosos sobre os cuidados durante a utilização } \\
\text { de transporte coletivo. } \\
\text { [ ] Orientar sobre limpeza e desinfecção dos } \\
\text { utensílios, equipamentos, mobílias e outros no espaço } \\
\text { compartilhado. } \\
\text { [ ] Orientar que alimentos sejam trazidos de casa e } \\
\text { consumidos individualmente, sem compartilhar com os } \\
\text { amigos. } \\
\text { [ ] Monitorar a adesão às medidas de segurança } \\
\text { transmitidas. }\end{array}$ \\
\hline
\end{tabular}

Quadro 2 - Diagnóstico, resultados e intervenções de enfermagem para prevenir a covid-19 em atividades grupais (FOCO NO IDOSO).

\begin{tabular}{|c|c|c|c|}
\hline $\begin{array}{l}\text { Diagnóstico de } \\
\text { Enfermagem }\end{array}$ & $\begin{array}{l}\text { Resultados de } \\
\text { Enfermagem (NOC) }\end{array}$ & $\begin{array}{l}\text { Intervençōes de } \\
\text { Enfermagem (NIC) }\end{array}$ & Atividades/Prescrição de Enfermagem \\
\hline $\begin{array}{l}\text { [ ] Comportamento } \\
\text { de saúde propenso } \\
\text { a risco }\end{array}$ & $\begin{array}{l}\text { [ ] Comportamento } \\
\text { de busca da saúde } \\
\text { Escore: } \\
\text { [ ] raramente } \\
\text { [ ] algumas vezes } \\
\text { [ ] frequentemente } \\
\text { [ ] consistentemente }\end{array}$ & $\begin{array}{l}\text { [ ] Modificação do } \\
\text { comportamento }\end{array}$ & $\begin{array}{l}\text { [ ] ldentificar o comportamento do idoso a ser modificado } \\
\text { [ ] Determinar a motivação do idoso para mudar o } \\
\text { comportamento, por meio do diálogo e de informações } \\
\text { adequadas sobre a prevenção do contágio. } \\
\text { [ ] Reforçar decisões construtivas sobre as necessidades de } \\
\text { saúde } \\
\text { [ ] Dar reforço positivo para os comportamentos } \\
\text { adequados em prevenção do risco de contágio. } \\
\text { [ ] Estimular a aprendizagem sobre prevenção do risco de } \\
\text { contágio para a desejada mudança de comportamento } \\
\text { [ ] Estimular os idosos a disseminarem as informações sobre } \\
\text { saúde entre os pares, familiares e comunidade. }\end{array}$ \\
\hline
\end{tabular}


Continuação do Quadro 2

\begin{tabular}{|l|l|l|l|}
\hline $\begin{array}{l}\text { Diagnóstico de } \\
\text { Enfermagem }\end{array}$ & $\begin{array}{l}\text { Resultados de } \\
\text { Enfermagem (NOC) }\end{array}$ & $\begin{array}{l}\text { Intervenções de } \\
\text { Enfermagem (NIC) }\end{array}$ & Atividades/Prescrição de Enfermagem \\
\hline $\begin{array}{l}\text { ( ) Conhecimento } \\
\text { deficiente }\end{array}$ & $\begin{array}{l}\text { [ ] Conhecimento: } \\
\text { segurança pessoal }\end{array}$ & $\begin{array}{l}\text { [ ] Educação em } \\
\text { saúde }\end{array}$ & $\begin{array}{l}\text { [ ] Possibilitar acesso a informação adequada } \\
\text { [ ] Explicar a fisiopatologia da doença (COVID-19) e sua } \\
\text { relação com as formas de contágio } \\
\text { [ ] Oferecer tempo ao idoso para que faça perguntas e } \\
\text { discuta suas preocupações } \\
\text { [ ] Enfatizar os benefícios, imediatos ou a curto prazo, a } \\
\text { serem obtidos por comportamentos de segurança pessoal. } \\
\text { [ ] Usar materiais ilustrativos como cartilhas, cartazes, } \\
\text { vídeos, banner com orientações e outros. }\end{array}$ \\
\hline $\begin{array}{l}\text { Escore: } \\
\text { [ ] ] moderado } \\
\text { [ ] substancial } \\
\text { [ ] vasto }\end{array}$ & &
\end{tabular}

\section{Estratégias para o Cuidado em Grupo com Pessoas Idosas}

O planejamento das estratégias deve considerar o perfil dos idosos que participam do grupo e suas necessidades específicas, considerando sua capacidade de locomoção, audição, visão e comunicação. Também seus acompanhantes devem ser atendidos em suas necessidades específicas. Um protocolo de acesso, acoIhimento, dinâmica das atividades e lanche no encerramento da reunião deve ser pensado antecipadamente, para garantir a provisão dos materiais necessários e o preparo do ambiente.

Considerando uma revisão sistemática de literatura com 24 estudos relacionados à pandemia de COVID-19, epidemias anteriores de Severe Acute Respiratory Syndrome (SARS) e Síndrome Respiratória do Oriente Médio (MERS) em ambientes de atenção à saúde e em outros ambientes, os autores referem que distanciamento social, uso de máscaras faciais e proteção para os olhos foram medidas recomendáveis para a proteção contra COVID-19. Os autores enfatizam que as medidas não conferem proteção completa, e toda intervenção requer a avaliação de riscos e considerações contextuais relacionadas à realidade em questão ${ }^{(13)}$.

Dessa forma, destaca-se a avaliação do potencial de risco de cada pessoa idosa na retomada das atividades de grupo com base nas recomendações da Organização Mundial de Saúde ${ }^{(14)}$ com estratégias e orientações que os enfermeiros devem repassar aos idosos e familiares por meios diversos (cartilhas, panfletos, cartazes) e retomados durante as reuniões online ou presenciais com todas as medidas.

\section{Decisões a tomar antes de sair de casa}

- avalie se não teve contato com alguma pessoa contaminada ou com sintomas da COVID-19; caso SIM, permaneça em casa para sua proteção e das outras pessoas que se encontrarão no grupo ou no trajeto até o grupo;

- certifique-se de levar sua própria água e lanche, se tiver de lanchar fora de casa;

- proteja-se das intempéries do clima mantendo-se agasalhada em caso de frio ou chuva;

- não esqueça do álcool gel 70\% na bolsa;

- dê preferência para saídas curtas para atividades específicas, como, por exemplo, participar da reunião do grupo.

\section{Transporte para os encontros do grupo}

- no ponto de ônibus busque o local mais arejado para ficar;

- evite tocar as superfícies do transporte; caso precise tocar, assim que puder, ao acomodar-se no assento, higienize suas mãos com álcool gel 70\%, que deverá estar em local acessível na sua bolsa;

- escolha horários com menos movimento de passageiros, sempre que possível;

- mantenha distância de dois metros das pessoas dentro do transporte e nos locais de circulação de pessoas;

- evite compartilhar o banco do ônibus com outras pessoas que não sejam do seu convívio doméstico; 
- se possível deixe um assento de distância entre você e a outra pessoa;

- ao sair do transporte, higienize suas mãos com álcool gel;

- as janelas do veículo devem ser mantidas abertas para aumentar a circulação do ar;

- planeje sua viagem; utilize o meio de transporte público apenas quando outros meios não estiverem disponíveis (dê preferência a transportes individuais e caminhadas, quando possível).

\section{Cuidados com a máscara}

- use máscara sempre que sair de casa;

- de preferência utilize máscaras cirúrgicas e, na falta desta, utilize máscara de pano duplo que seja confortável e que se mantenha fixa o tempo todo;

- as máscaras devem ser trocadas sempre que úmidas ou sujas, por isso carregue sempre mais uma com você, dentro de embalagem plástica;

- não toque a parte frontal da máscara;

- não toque o rosto, mesmo utilizando a máscara;

- higienize as mãos imediatamente, sempre que retirar a máscara;

- a máscara é de uso individual;

- mesmo utilizando máscara, mantenha o distanciamento físico;

- lave a máscara com água e sabão.

\section{Refeições fora de casa}

- lave as mãos ou passe álcool gel antes de fazer o lanche ou tomar a sua água;

- leve consigo uma pequena garrafa com a bebida que irá tomar durante a reunião ou para o lanche, como água ou suco - é muito importante manter-se hidratada(o);

- o alimento também deve ser levado de casa e acondicionado em vasilhas ou sacos plásticos; não troque alimentos com os colegas;

- o lixo deve ser desprezado dentro da lixeira conforme orientação do local.

\section{Distanciamento Social}

- conforme as evidências apresentadas e amplamente divulgadas, quanto maior a distância entre as pessoas, menor o risco de contaminação;

- mesmo sabendo da importância e da troca de energia que um abraço promove, cumprimente seus colegas e amigos com um aceno ou uma reverência demonstrando o prazer e a alegria do encontro;

- atenda às recomendações do coordenador e sente-se mantendo a adequada distância de seus colegas e amigos.

\section{Medidas de Higiene}

- ao chegar ao local do encontro do grupo, lave suas mãos com água e sabão e dirija-se para a sala;

- ao utilizar o sanitário, higienize-o com papel toalha e álcool gel, que deverá estar disponível, antes e depois de usá-lo;

- higienize suas mãos com água e sabão por pelo menos 20 segundos e dirija-se à sala de reuniões;

- evite tocar em superfícies e use o álcool gel 70\%, quando necessário;

- mantenha a máscara no rosto, cobrindo boca e nariz, durante o tempo todo;

- evite tocar o rosto e a máscara. 


\section{Estratégias e Medidas de Reestruturação dos Espaços Físicos e das Atividades de Grupo}

As medidas de reestruturação dos espaços para retorno às atividades têm o intuito de garantir a segurança do idoso, do ambiente, da circulação, do manejo dos profissionais e o gerenciamento dos dados e divulgação de informações.

Acredita-se que a construção conjunta de conhecimentos acerca da convivência com a doença e as vivências em tempos de pandemia trarão subsídios para reorganizar os espaços e as rotinas nos locais que acolhem os idosos em atividades grupais. Criar objetivos gerais de estruturação dos serviços pode auxiliar na implementação do processo de enfermagem em tempos de pandemia. Por exemplo:

Elaborar Protocolos de Segurança do idoso no âmbito da instituição; realizar ações de prevenção e gerenciamento com informações sobre as medidas adotadas para circulação nos espaços; realizar atividades de Educação Permanente com os profissionais da saúde; utilizar tecnologias para atividade educativa; realizar grupos de educação em saúde virtuais; ofertar um espaço de diálogo e reflexão permanente sobre o impacto da pandemia na saúde mental por meio da relação dialógica profissional-idoso.

\section{Limitações}

As principais limitações do presente estudo se prendem às evidências pouco robustas, devido ao curto período de tempo de início da pandemia e da escassez de publicações disponíveis. No entanto, o material obtido já permite conjecturar possível retorno dos grupos de idosos, com certa segurança. O"novo" normal precisa ser incorporado pela população e pelos profissionais de saúde para permitir o retorno gradual das atividades em grupo.

\section{Contribuições para a enfermagem}

O estudo promove a sistematização da assistência de enfermagem baseada no autocuidado de Orem para grupos de idosos na comunidade em tempos de pandemia de doença infectocontagiosa. São propostos diagnósticos de enfermagem, intervenções e prescrição de enfermagem para auxiliar o enfermeiro que trabalha com grupos de idosos. Além disso, são apresentadas estratégias específicas de enfrentamento da COVID-19.

\section{CONSIDERAÇÕES FINAIS}

Diante do exposto, acredita-se que o retorno dos idosos às atividades grupais exigirá um esforço conjunto dos enfermeiros e equipes para reorganizar a estrutura física e organizar as atividades com respeito às estratégias de prevenção à SARS-CoV-2.

Atualmente o profissional de enfermagem enfrenta um grande desafio: as condições crônicas de saúde, o envelhecimento da população e o avanço da pandemia do novo coronavírus requerem cuidados inovadores e nos levam a refletir sobre a demanda de atendimento especializado e se os profissionais estão preparados para prestá-lo na atual conjuntura.

Para isso, a nossa reflexão sobre as competências e o preparo dos profissionais deve emergir de diversas concepções: habilidades adquiridas, formação técnico-científica e o acesso estimulado e facilitado à qualificação profissional fazem parte de um conjunto de medidas que, a nosso ver, devem ser implementadas pelos gestores, na forma de educação em serviço e outras, em conjunto com os grupos sob sua supervisão.

Diante desta nova situação imposta pela pandemia, com as incertezas sobre a forma de transmissão, tratamento e prevenção da COVID-19, é oportuno pensar um novo normal. Adotar as medidas de prevenção, como distanciamento social, uso constante de máscara e higienização das mãos é imperativo para que seja possível o retorno de atividades em grupo. Destarte, o papel do enfermeiro é promover o autocuidado dos idosos, familiares, comunidade e equipes de atendimento por meio da educação em saúde e supervisão da implementação dos protocolos de segurança pessoal e nas instituições. 
Assim, identificar e estimular a busca pelas competências clínicas e a forma como os enfermeiros as adquirem é um recurso relevante para instituir e reforçar programas que visem à capacitação profissional, o que os gestores devem ter como sua prioridade. Muitas instituições têm alta rotatividade de pessoal e enfermeiros recém-formados responsáveis por diferentes unidades assistenciais, o que muitas vezes os impede de desenvolver práticas clínicas avançadas.

Verifica-se que a apreensão de competências clínicas se dá em grande parte pelas práticas profissionais diante das quais os enfermeiros são colocados no seu dia a dia; portanto, o treinamento técnico e a educação em serviço nos parecem estratégia ideal para atingir esses objetivos.

\section{REFERÊNCIAS}

1. Ministério da Saúde (BR). Painel Coronavírus [Internet]. 2020 [cited 2020 Aug 11]. Available from: https: //covid.saude.gov.br/

2. Sociedade Brasileira de Geriatria e Gerontologia (SBGG). Posicionamento-sobre-covid-19-sociedade-brasileira-degeriatria-e-gerontologia-Atualizacao-15-03-2020[Internet]. 2020 [cited 2020 Jul 19]. Available from: https://sbgg.org.br/ posicionamento-sobre-covid-19-sociedade-brasileira-de-geriatria-e-gerontologia-sbgg-atualizacao-15-03-2020/

3. Alvarez AM, Gonçalves LHT, Schier J, Hammershimidt KSA, Souza BC, Valcarenghi RV. Grupo de apoio às pessoas com Doença de Parkinson e seus familiares. Rev Eletrôn Extensão-Extensivo. 2016;13(suppl-22):92-101 https://doi. org/10.5007/1807-0221.2016v13n22p92

4. Schier J, Gonçalves LHT, Alvarez AM. Tecnologia socioeducativa de enfermagem Hospitalar In: Nietsche EA, Teixeira E, Medeiros HP, (Orgs.). Tecnologias Cuidativo-Educacionais: uma possibilidade para o empoderamento do (a) enfermeiro (a). Ed. Porto Alegre: Moriá; 2014. 147-160 p.

5. Ministério da Saúde (BR). Secretaria de Atenção à Saúde. Departamento de Ações Programáticas e Estratégicas. Área Técnica Saúde do Idoso. Atenção à saúde da pessoa idosa e envelhecimento[Internet]. Série Pactos pela Saúde. 2006 [cited 2020 Jul 15]. Available from: http://bvsms.saude.gov.br/bvs/publicacoes/atencao_saude_pessoa_idosa_envelhecimento_v12.pdf

6. Ministério da Saúde (BR). Secretaria de Atenção à Saúde Departamento de Ações Programáticas e Estratégicas. Orientações técnicas para a implementação de Linha de Cuidado para Atenção Integral à Saúde da Pessoa Idosa no Sistema Único de Saúde - SUS [Internet]. 2018 [cited 2020 Jul 15]. Available from: https://bvsms.saude.gov.br/bvs/ publicacoes/linha_cuidado_atencao_pessoa_idosa.pdf

7. Ministério da Saúde (BR). Portaria n 2.436, de 21 de setembro de 2017. Aprova a Política Nacional de Atenção Básica, estabelecendo a revisão de diretrizes para a organização da Atenção Básica, no âmbito do Sistema Único de Saúde (SUS) [Internet]. 2017 [cited 2020 Jul 15]. Available from: https://bvsms.saude.gov.br/bvs/saudelegis/gm/2017/prt2436_22_09_2017.html

8. Ministério da Saúde (BR). Secretaria de Atenção à Saúde. Política Nacional de Práticas Integrativas e Complementares no SUS[Internet]. 2006 [cited 2020 Jul 15]. Available from: https://bvsms.saude.gov.br/bvs/publicacoes/pnpic.pdf

9. Leite ES, Pimenta CJL, Costa MS, Oliveira FB, Moreira MASP, Silva AO. Assistive technology and active aging according to professionals working in community groups. Rev Esc Enferm USP. 2018;(suppl52):1-8. https://doi.org/10.1590/ S1980-220X2017030903355

10. Kurz MLB, Morgan, MIO. Proteção social básica e grupos de convivência: garantia de inclusão social da pessoa idosa. Anais, Ciência, Reflexividade e (In) certezas [Internet]. 2012 [cited 2020 Jul 16];23(6). Available from: http://www.unicruz.edu.br/ seminario/anaisArtigos.php.

11. Naranjo-Hernández, Y. Modelos metaparadigmáticos de Dorothea Orem. Rev Arch Med Camagüey [Internet]. 2020 [cited $2020 \mathrm{Jul}$ 16]; 23(6). Available from: http://scielo.sld.cu/pdf/amc/v23n6/1025-0255-amc-23-06-814.pdf

12. McEwen M, Wills EM. Bases teóricas de Enfermagem. 4 Ed. Artmed. Porto Alegre, 2016.

13. Chu DK, Akl EA, Duda S, Solo K, Yaacoub S, Schunemann HJ. Physical distancing, face masks, and eye protection to prevent person-to-person transmission of SARS-CoV-2 and COVID-19: a systematic review and meta-analysis. Lancet [Internet]. 2020 [cited 2020 Jul 16];395. Available from: https://www.thelancet.com/action/showPdf?pii=S0140-6736\%2820\%2931142-9

14. World Health Organization (WHO). Recomendações sobre o uso de máscaras no contexto da COVID 19. Orientações provisórias 5 de junho de 2020[Internet]. 2020 [cited 2020 Jul 27]. Available from: https://apps.who.int/iris/bitstream/ handle/10665/332293/WHO-2019-nCov-IPC_Masks-2020.4-por.pdf?sequence=33\&isAllowed=y 